\title{
Psicologia Escolar na Universidade: relato de um projeto de extensão
}

\author{
Vanessa Aparecida Alves de Lima1, http://orcid.org/0000-0002-9668-5926
}

\section{Resumo}

A psicologia escolar crítica propõe o resgate das dimensões escolar, social e histórica na compreensão do fracasso escolar, numa abordagem interdisciplinar e grupal. Nesta perspectiva, este é um relato de grupos de universitários de cursos de engenharia, em uma instituição federal. Foram realizados grupos de aconselhamento psicológico, orientação vocacional e técnicas de estudo. O grupo de técnicas de estudo foi o único que permaneceu completo até o final dos encontros previstos, quando se pode discutir a complexidade do cotidiano educacional, o sentimento de fracasso escolar e os papeis introjetados de culpabilização.

Palavras-chave: Psicologia escolar; ensino superior; fracasso escolar.

\section{School Psychology in the University: report of an extension project}

\begin{abstract}
Critical school psychology proposes the rescue of the school, social and historical dimensions in the understanding of school failure, in an interdisciplinary and group approach. In this perspective, this is an account of university groups of engineering courses, in a federal institution. Psychological counseling groups, vocational guidance, and study techniques have carried out. The group of study techniques was the only one that remained complete until the end of the planned meetings when one can discuss the complexity of daily education, the feeling of school failure and the introjected roles of the blame.
\end{abstract}

Keywords: School psychology; higher education; school failure.

\section{Psicología Escolar en la Universidad: relato de un proyecto de extensión}

\section{Resumen}

La psicología escolar crítica propone el rescate de las dimensiones escolar, social e histórica en la comprensión del fracaso escolar, en un abordaje interdisciplinar y grupal. En esta perspectiva, este es un relato de grupos de universitarios de cursos de engeñaría, en una institución federal. Se realizaron grupos de asesoramiento psicológico, orientación vocacional y técnicas de estudio. El grupo de técnicas de estudio fue el único que permaneció completo hasta el final de los encuentros previstos, cuando se puede discutir la complexidad del cotidiano educacional, el sentimiento de fracaso escolar y los papeles introyectados de culpabilidad.

Palabras clave: Psicología escolar; educación superior; fracaso escolar. 


\section{Introdução}

Este relato de experiência parte da concepção de que o acompanhamento ao aluno pelas instituições educacionais deve ser integral, e no que tange às universidades, não basta a oferta de ensino público e gratuito, é necessário suporte psicológico, pedagógico e de assistência social para os alunos, pois essa instituição congrega diferentes grupos identitários e sociais.

Acredito em uma Psicologia Escolar que enfrente e minimize a prática institucional medicalizante e patologizante (Collares \& Moysés, 1994) que culpabiliza os alunos pelos fracassos acadêmicos (Tanamachi, 2000; Souza, B., 2007a; Souza, 1997). Nessa perspectiva, após minha experiência como docente em cursos de Psicologia, inclusive com ensino e estágio supervisionado em Psicologia Escolar, me vi em um jovem campus federal (fundado em 2008), onde todos os cursos são da área de Engenharia.

Nesse campus não havia, em 2014, suporte institucional para alunos e professores no que tange à compreensão da queixa escolar, sendo que na instituição e, especificamente nesse campus, há grande índice de reprovação e evasão nos cursos de Engenharia, especialmente nas fases iniciais,quando os acadêmicos se deparam com as disciplinas de Cálculo I e II, Física I e II e Álgebra (os índices de reprovação são em média $70 \%$, para alguns períodos, segundo dados do Sistema de Controle Acadêmico da Graduação).

Chegando à instituição como Professora Ensino Superior, não tinha responsabilidades nessa área, mas sensibilizei-me com a situação a partir da exposição feita pelas Assistentes Sociais do Programa de Assistência Estudantil do Campus. Iniciei então um trabalho de pesquisa diagnóstica da instituição, conhecendo-a, os alunos, professores, gestores e o contexto.

Sobre a gestão, compreendi que havia interesse em abordar a situação da queixa escolar, mas ainda lida com uma diversidade de questões administrativas, como por exemplo, o fato de não ter sede própria, realizando suas atividades em prédios provisórios (alugados), distantes uns dos outros.

Os professores são um grupo heterogêneo, alguns jovens titulados sem experiência docente, outros experientes em atividades industriais. Heterogêneos também são quanto ao desempenho didático e à concepção epistemológica do processo de ensino-aprendizagem, havendo grande tendência à concepção inatista/empirista de aprendizagem com um ensino diretivo (Becker, 1993, 2003) e a consequente culpabilização do aluno(Souza B., 2007b; Souza, 1997), enquanto outros se mostram interessados e preocupados com a situação de evasão/reprovação.

Ofertei então, um semestre depois de estar efetivamente na instituição, um Projeto de Extensão que envolveu um grupo de Aconselhamento Psicológico na abordagem rogeriana (Rogers, 1992), um grupo de Orientação Profissional - já que uma das queixas feitas por alunos e professores, é que os acadêmicos não têm vocação para a engenharia - e um grupo de Técnicas de Estudo, todos com uma média de 12 encontros semanais.

Houve grande procura e interesse nos três grupos, com uma média de 20 a 30 inscritos em cada um deles, mas qual não foi minha surpresa e das Assistentes Sociais, o fato de no primeiro dia de cada grupo, o comparecimento dos interessados ter sido baixo e até mínimo: quatro no grupo de Aconselhamento Psicológico, dois no grupo de Orientação Vocacional e 12 no grupo de Técnicas de Estudo. Acreditamos que tal fato ocorreu porque há desconhecimento acerca da contribuição possível da Psicologia Escolar e/ou do papel de técnicos educacionais na instituição.

Os dois sujeitos do grupo de Orientação Vocacional, depois de quatro encontros, deram-se por satisfeitos com as discussões realizadas. Um deles chegou a novas estratégias para lidar com o cotidiano institucional, reafirmando sua escolha pelo curso, e o outro, transferiu-se para outro campus da mesma instituição para fazer engenharia de produção (que não há neste campus).

Dos participantes do grupo de Aconselhamento Psicológico, que tinha como objetivo lidar com situações que, segundo o encaminhamento da Assistência Estudantil, não tinha como queixa a instituição, mas situações anteriores ao ingresso nela, houve a solicitação de dois participantes de acompanhamento individual, pois não se sentiam à vontade para a partilha no grupo. Posteriormente compreendi que tal pedido relacionava-se ao fato de que ambas disputavam o mesmo namorado. Os encontros de Aconselhamento Psicológico foram encerrados dentro do previsto. Os outros dois participantes também eram integrantes do grupo de Técnicas de Estudo e ficaram frequentando apenas os encontros neste.

O grupo de Técnicas de Estudo, este sim, constituiu-se num grupo de Psicologia Escolar com enfrentamento da queixa escolar. Usando como mote das discussões técnicas de estudo da neuropedagogia (Piazzi, 2008a, 2008b), houve oportunidade para os participantes (acadêmicos da várias fases) realizarem este enfrentamento através de:

- Discussão acerca da complexidade do cotidiano escolar: esta é percebida em vários aspectos, como por exemplo, a burocracia e o sistema rígido de avaliação dos professores.

- Refletir sobre a própria historicidade escolar e a relação da mesma com o sistema de aproveitamento escolar da instituição: o sistema de avaliação da instituição, por Índice de Aproveitamento Escolar, é considerado opressivo. Afirmam que escolheram Engenharia por que ao longo da vida escolar eram bons em ciências exatas, mas na instituição enfrentam sucessivas reprovações em disciplinas que se consideravam competentes, como física. O sentimento de (in)competência foi muito discutido no grupo, surgiu em todos os encontros, e o comparativo com a imagem que tinham de si foi uma constante. Não são raros quadros depressivos, surtos de pânico e uso de medicação controlada, com 
e sem acompanhamento médico, por exemplo, cheirar Ritalina parece ser uma prática aceitável para ter melhor desempenho nas provas.

- Ponderar sobre as crenças e preconceitos relativas ao desenvolvimento pessoal e profissional na construção do conhecimento: os alunos manifestaram que nas discussões do grupo puderam expressar os estresses da vivência institucional e reconstruíram, entre outros, o conceito de competência. Para muitos, o fracasso (reprovação em algumas disciplinas), que estava causando muita angústia e sofrimento, passou a ser vivido como processo, no desenvolvimento acadêmico (Piaget, 1982, 1990). Na verdade, muitos já haviam introjetado a imagem de fracassado. Agora, se apoiam nos projetos futuros e no gostar de exatas, para permanecer no curso/instituição.

Esses participantes têm, eventualmente, dado retorno de seus progressos na instituição, e consideram que continuam se desenvolvendo nela.

\section{Considerações Finais}

A partir de 2015 a instituição conta com uma Psicóloga para o atendimento aos alunos que participam dos programas de bolsa da Assistência Estudantil, e essa profissional, no ano de 2016, montou um grupo de apoio psicopedagógico aos demais.

A instituição tem, especialmente a partir do corpo de Coordenadores de Curso, preocupação e interesse em lidar com a problemática da queixa escolar (reprovação e evasão), mas há dificuldade de fazer isto de forma transversal, em grupos de discussão do sistema de avaliação e planejamento integrado (Tanamachi, 2000). Mas a disposição de fazê-lo já é um excelente sinal dessa jovem instituição.

\section{Referências}

Becker, F. (1993). Modelos pedagógicos e modelos epistemológicos. Paixão de Aprender, (5), 18-23.
Becker, F. (2003). A origem do conhecimento e a aprendizagem escolar. Porto Alegre: Artmed.

Collares, C. A. L.; Moysés, M. A. A. (1994). A transformação do espaço pedagógico em espaço clínico. Fundação para o Desenvolvimento da Educação, 23, 25-31.

Piaget, J. (1982). O nascimento da inteligência na criança (4a. ed.). Rio de Janeiro: Zahar.

Piaget, J. (1990). O nascimento do símbolo na criança (3a. ed.). Rio de Janeiro: LTC.

Piazzi, P. (2008a).Aprendendo inteligência(2a. ed.). São Paulo: Aleph.

Piazzi, P. (2008b). Estimulando inteligência (2a. ed.). São Paulo: Aleph.

Rogers, C. (1992). Terapia centrada no cliente São Paulo: Martins Fontes.

Souza, B. P. (2007a). Funcionamentos escolares e a produção de fracasso escolar. In: Souza, B. P. (Org.), Orientação à queixa escolar(pp. 241-277).São Paulo: Casa do Psicólogo.

Souza, B. P. (Org.) (2007b). Orientação à queixa escolar. São Paulo: Casa do Psicólogo.

Souza, M. P. R. (1997). A queixa escolar e o predomínio de uma visão de mundo. In: Machado A. M.; Souza, M. P. R. (Orgs.),Psicologia escolar: em busca de novos rumos(pp. 19-37). São Paulo: Casa do Psicólogo.

Tanamachi, E. R. (2000). Mediações teórico-práticas de uma visão crítica em psicologia escolar. In: Tanamachi, E. R.; Souza, M. P. R.; Rocha, M. L. (Orgs.), Psicologia e educação: desafios teóricopráticos (pp. 73-103). São Paulo: Casa do Psicólogo. 